\title{
Dynamic Linkage amongst Oil, Gold, Exchange Rates and Stock Markets in Africa: Evidence from Volatility of Major African Economies
}

\section{Thabani H Mhlongo}

University of South Africa - Science Campus

John Olutunji Olaomi ( $\nabla$ olaomjo@unisa.ac.za )

University of South Africa - Science Campus https://orcid.org/0000-0002-1180-3189

\section{Research}

Keywords: African stock markets, exchange rates, co-movement, copula-DCC GARCH, GlostenJagannathan-Runkle (GJR)

Posted Date: June 30th, 2021

DOl: https://doi.org/10.21203/rs.3.rs-594726/v1

License: (c) (i) This work is licensed under a Creative Commons Attribution 4.0 International License. Read Full License 


\section{Dynamic Linkage amongst Oil, Gold, Exchange Rates and Stock Markets in Africa: Evidence from Volatility of Major African Economies}

Thabani H. Mhlongo

(mhlongoth@gmail.com)

and

John O. Olaomi

(olaomjo@unisa.ac.za)* 
changes amongst these markets between the years 2000 and 2019 using a copula based DCC 1

GARCH framework for a sample of twenty highest ranked African economies by nominal 2 GDP. The results show evidence of time varying co-movement amongst these markets that 3 tend to increase during times of turbulence in sampled markets. Dynamic relations are found 4 to be quantitatively and relatively substantial for economies of Egypt, South Africa, Tanzania, 5 Libya and Zambia. The results from this study would improve the risk management decisions by investment managers, individual investors and investment regulators.

Key words: African stock markets, exchange rates, co-movement, copula-DCC GARCH, 9 Glosten-Jagannathan-Runkle (GJR).

\section{Introduction}

Commodity trading is a strategic and globally prominent economic activity that is used on a micro and macroeconomic level for reasons such as generating income, industrial input, 15 commercial demand and managing various risks. Africa is a commodity rich continent in which 16 the extractive industry plays a crucial role and this is because a number of its constituents have $\quad 17$ a high concentration of exports consisting of and dependent on commodities (United Nations 18 Conference on Trade and Development 2019). The high concentration of commodity exports 19 has meant that both low and high volatility in the price of a single or group of commodities 20 could have detrimental and beneficial effects on economic growth (Deaton 1999). Crude oil 21 and gold are examples of commodities that account for a significant portion of either primary 22 or secondary goods exported by $55 \%$ of economies in the African continent (African Economic 23 
Outlook 2017). Price and volatility shocks of both crude oil and gold have been shown to have a relationship with each other and conditionally with economic growth inducing variables in- 2 cluding exchange rates and stock markets (Ciner, Gurdgiev and Lucey 2013; Baur and 3 McDermott 2016; Junttila, Pesonen and Raatikainen 2018). The conditional relationship 4 amongst exchange rates, stock markets, crude oil and gold is based on factors such as levels of 5 income, demand and availability (Milani 2011; Arouri, Jouini and Nguyen 2012; World Bank 6 Group 2018). Commodities such as oil and gold have a unidirectional impact towards stock $\quad 7$ markets that is amplified by dependence, diversification and size of an economy or industry 8 (Arouri, Jouini and Nguyen 2012; Degiannakis, Filis and Floros 2013; Behmiri and Manera 9 2015). For example, crude oil is able to affect discount rates and present value of stocks in a 10 market by changing costs and cash flows (Degiannakis, Filis and Arora 2018). Crude oil shocks 11 also distinctively affect the currencies markets based on an economy's net-exporting status 12 (Basher, Haug and Sadorsky 2016). Due to gold's predominant pricing in a stable currency ( 13 the United States of America's dollar), the commodity acts as an alternative investment asset 14 with conditional hedging qualities in stock markets of large emerging economies and exchange 15 rates in developed markets (Baur and McDermott 2010; Joy 2011; Ciner, Gurdgiev and Lucey 16 2013; Reboredo 2013; Raza et al. 2016). The long and intertwined history of gold, financial 17 markets and money has resulted in gold's regular prominence in investment and monetary dis- $\quad 18$ cussions. (O’Connor, Lucey, Batten and Baur 2015).

Central banks, amongst other activities, also provide protection, confidence and stability 20 for the currencies they oversee by holding as part of reserves assets such as commodities, gold 21 specifically. The reserves are generally kept with the aim of circumventing unexpected adverse 22 currency movements from capital flows. The change in an economy's effective exchange rate 23 imposes or is caused by changes in its stock market (Chkili and Khuong 2014; Moore and 24 Wang 2014). The "flow-oriented" and "stock-oriented" models suggest alternative theories that 25 
relate an economy's currency to its stock market. The "flow-oriented" model suggests that, 1 changes in exchange rates affect an economy's stock market through changes emanating from 2 relative price and demand for domestic goods arising from international trade and competitive- 3 ness. International competitiveness impacts economic output, income and investment decisions 4 that pertain to future cash flows, affecting the present value of stock prices (Dornbusch and 5 Fischer 1980). The "stock-oriented" model suggests that, trading activities in the equities mar- 6 $\begin{array}{lll}\text { ket affect the wealth of individuals who timeously balance their portfolios and stock holdings } & 7\end{array}$ by changing their demand for means to transact and trade globally, such as financial assets in 8 the form of money. The resulting change in money supply and demand equilibrium affects 9 interest rates, hence allowing for misalignment in exchange rates markets (Branson 1981; 10 Frankel 1983). Though the relationship between real exchange rate misalignment and eco- 11 nomic growth exists, there are certain optimal real exchange rate threshold levels at which 12 undervaluing or overvaluing a currency can be associated with either positive or negative eco- 13 nomic growth and can directly affect the stock market (Elbadawi, Kaltani and Soto 2012; Yan 14 and Yang 2012; Couharde and Sallenave 2013; Tang 2015). 15

This paper uses a copula based dynamic conditional correlation GARCH approach to ex- 16 amine whether there is a possibility of a dynamic influential and dependence relationship 17 amongst commodities, currencies and equities in African economies. The study uses crude oil 18 and gold as commodity market proxies because of their prevalence in the African economies' 19 exports market. The study also uses exchange rates and stock markets of African economies 20 that were the highest ranked by income over the sample period spanning 2000 and 2019. The 21 results from the studied relationship mainly add to the existing understanding and offer broader 22 insights on the impact commodity price fluctuations have on each other and on economic var- $\quad 23$ iable shocks especially for developing economies that are price takers with moderate or high 24 total export concentration consisting of commodities. Also, the inclusion of gold in the analysis 25 
gives weight to the ability of this paper to make concluding remarks regarding commodities 1 exported in the African continent.

\section{Literature review}

Researchers have over the years rationalised the linkages between commodities and pertinent economic variables that are influential to economic performance especially that of de- 5 veloping and in transit economies. Pindyck and Rotemberg (1990) were amongst the first to 6 argue that, within the commodities market, linkages in the form of co-movements exist even $\quad 7$ amongst unrelated commodities. However, the co-movements in the commodities market does 8 not imply that there exist homogeneity in the overall market's risk and return structure (Erb 9 and Harvey 2005; Adams, Füss and Kaiser 2011). The research by Deaton (1999); Ncube, 10 Tessema and Gurara (2014); and Behmiri and Manera (2015) however further offered addi- 11 tional insights by arguing that in varying sample periods and market segments, exogeneous 12 global factors such as economic shocks, natural disasters and wars tend to influence co-move- 13 ments in the commodities market. Varying frameworks and sampling approaches have shown 14 that the commodities' market also influence economic variables including exchange rates and 15 stock markets. Filis, Degiannakis and Floros (2011) using a dynamic conditional correlation 16 (DCC) GARCH framework, find negative time varying influential relationship from changes 17 in oil prices towards stock markets that is similar for both importing and exporting economies. 18 Wang, Wu and Yang (2013) using a structural vector autoregressive (VAR) approach find that 19 the response relationship is conditional on whether the economy is an exporter or importer of 20 oil. Reboredo and Ugolini (2016) show how the size of an oil shock plays a role in the influence 21 oil price changes have on stock markets by showing that varying shock quantiles have differing 22 relational impact between the two markets. Zankawah and Stewart (2019) use the economy of 23 Ghana and a Baba, Engle, Kraft and Kroner (BEKK) GARCH model to show how the treatment 24 of crude oil in the modelling stages either as an endogenous or exogenous variable can show 25 
varying conclusions to the impact and relationship it has with stock markets, while that of crude 1 oil and currency is similar regardless of oil treatment. Crude oil has been shown to have a 2 negative co-movement relationship also with exchange rates of most economies. For instance, 3 Yang et al. (2018) and Bedoui et al. (2018) show that with the exception of Japan, there is a 4 negative relationship between crude oil and currency using GARCH-type models by sampling 5 currencies of Canada, UK, Europe, Japan and USA. Ciner, Gurdgiev and Lucey (2013) show 6 both gold and oil as having conditional safe haven properties due to each having a negative $\quad 7$ relationship with currencies during certain periods.

Choudhry, Hassan and Shabi (2015) and Nguyen et al. (2016) show how stock markets 9 of economies such as the United Kingdom, USA, Thailand and Singapore are influenced by 10 gold price changes. Adewuyi, Awodumi and Abodunde (2019) and Chkili (2016) respectively 11 show that the relationship between gold and stock market of Nigeria and BRICS economies 12 (Brazil, Russia, India, China and South Africa) is negative and has structural breaks. Jain and 13 Biswal (2016), Ahmed and Huo (2020), and Malandala and Olaomi (2021) show that both the 14 stock and exchange rate market of various emerging countries including India, Botswana, 15 Egypt, Ghana, Kenya, Morocco, Namibia, Nigeria, South Africa, Tunisia and Zambia are in- 16 fluenced by changes in commodity prices especially when using gold and oil as proxies of the 17 commodities market. There is vast literature that has shown the bivariate interaction between 18 stock markets and exchange rates. Ahmed (2014); Fowowe (2015); and Blau (2018) show that 19 for the economies they sampled, a unidirectional relationship is mainly found per economy. $\quad 20$ For example, Nigeria and China's currencies are shown to have an influence towards their 21 stock market while the opposite occurs in the Egyptian domestic market. 22

\section{Materials and Methods}


The data used consists of logarithmic transformed, end of month nominal prices of gold in USD per Troy ounce, crude oil in USD per barrel, sampled economies' local currencies' exchange rate per USD and primary stock market's main index as a proxy to stock market 3 performance $^{1}$. The sample period is from January 2000 to December 2019 and is of interest 4 because it covers both global events including the 2008 global financial crisis, oil price slump 5 of 2014 and country specific events such as changes in the structure of the currencies of Nige- 6 ria, Egypt and Zambia, and the replacement of the All share index with the GSE composite by 7 Ghana's stock exchange. We select the highest 20 ranking economies based on consistent and 8 significant contribution to the African continent's overall nominal GDP over the sampled period. The economies sampled include Algeria, Angola, Botswana, Cameroon, Democratic Republic of Congo (DRC), Côte d'Ivoire, Egypt, Ethiopia, Ghana, Gabon, Kenya, Libya, Mo- 11 rocco, Nigeria, South Africa, Sudan, Tanzania, Tunisia, Uganda and Zambia ${ }^{2}$. The data is 12 sourced from the International Monetary Fund's International Statistics, African Development Bank, Quandl, Stock Exchange in Botswana, Egypt, Algiers, and Nigeria, Annual Reports Ghana, Johannesburg Stock Exchange, Kenya's Capital Market Authority (CMA), Sanabelfs 15 Securities and Iress. Error! Reference source not found. is a basic statistics view of the sam- 16 pled univariates and offers statistics on the data's degree of asymmetry, kurtosis and $p$-values 17 of results from two normality tests, Jarque-Bera (JB) of Bera and Jarque (1981) and Shapiro-

\footnotetext{
${ }^{1}$ Regional currency, West African CFA Franc (XOF) and regional stock market, Bourse Régionale des Valeurs Mobilières (BRVM) are included and studied under Côte d'Ivoire and represent Benin, Burkina Faso, Guinea-Bissau, Mali, Niger, Senegal and Togo. Central African CFA Franc (XAF) representing Cameroon, Gabon, Central African Republic, Congo, Chad and Equatorial Guinea are also included under Côte d'Ivoire due to the equivalence between XAF and XOF.
}

\footnotetext{
2 The stock market and currencies data per economy includes: Algeria: DZAIR and Dinar (DZD); Angola: Kwanza (AOA); Botswana Domestic Companies (BSEDCI) and Pula (BWP); Côte d'Ivoire: BRVM Composite and West African CFA Franc (XOF); DR. Congo: Congolese Franc (CDF); Egypt : EGX 30 and Pound (EGP); Ethiopia: Birr (ETB); Ghana: GSE Composite/ALSI and Cedi (GHS); Kenya: NSE 20 Share and Shilling (KES); Libya Dinar (LYD); Morocco: All Share (MASI) and Dirham (MAD); Nigeria: All Share (NEASI) and Naira (NGN); South Africa All Share (SALSI) and Rand (ZAR); Sudan Khartoum 30 and Pound (SDG); Tanzania All Share (TSEASI) and Shilling (TZS); Tunisia: Tunindex and Dinar (TND); Uganda: All Share (USE) and Shilling (UGX);and Zambia: All Share (LUASI) and Kwacha (ZMW/ZMK).
} 
Wilks (SW) of Shapiro and Wilk (1965). Based on the skewness (asymmetry), kurtosis (lepto- 1 kurtic), SW and JB tests; none of the sampled variables can be regarded as being normally 2 distributed. Serial dependence and stationarity in the data are tested using, respectively, the 3 Ljung-Box and Augmented Dickey Fuller (ADF) tests and their results are also presented in 4 Error! Reference source not found.. The number of lags tested for the Ljung-Box test is 5 selected using an approach by Tsay (2010) which suggests selecting the natural log of the 6 length of the series. For the ADF test, the approach by Phillips and Perron (1989) is used to 7 select the truncation lag of most variables based on the length of the time series $(T)$, Lags $\max =8$

$12(T / 100)^{1 / 4}$. The stationary results are tested for the first 10 lags of each sampled uni- 9 variate, except for DZD, DZAIR, LUALSI (for which 8 lags was used); BRVM (at 9 lags); and 10 AOA and TZA (at 6 lags). The Ljung-Box test at 5\% level of significance suggests that varia- 11 bles such as crude oil; GHS and NGN have serial correlation hence a need to consider past 12 returns when analysing them.

\subsection{Methodology}

The copula MGARCH framework proposed by authors such as Lee and Long (2009), 15 amongst others, is chosen because it can separately capture conditional correlation and depend- 16 ence using a copula. The inference for margins (IMF) approach is used to estimate conditional 17 dependence to study the behavior of the univariates. Marginal distributions' parameters are 18 estimated using an ARMA $\left(p_{1}, q_{1}\right)$-GARCH $\left(p_{2}, q_{2}\right)$ model and this is due to the presence of 19 serial dependence and real values $p_{1}, q_{1}, p_{2}$ and $q_{2}$ are chosen based on the Akaike infor- $\quad 20$ mation criterion (AIC), behaviour of standardised residuals and ARCH test. The GJR-GARCH 21 of Glosten et. al. (1993) and E-GARCH of Nelson (1991) are each compared with the standard 22 GARCH model of Bollerslev (1986) using the AIC and loglikelihood statistics. The return, $r_{t}, \quad 23$ of each sampled variable can be expressed as an ARMA $\left(p_{1}, 0\right)$ as follows: 24 


$$
r_{t}=\beta_{0}+\sum_{i=1}^{p} \beta_{i} r_{t-i}+\varepsilon_{t}, \quad \varepsilon_{t} \sim N\left(0, \sigma_{t}^{2}\right)
$$

$\sigma_{t}^{2}$ can be expressed respectively using the GJR and exponential GARCH as follows:

$$
\sigma_{t}^{2}=\omega_{0}+\sum_{i=1}^{x}\left(\propto_{i}+\gamma_{i} N_{t-i}\right) \varepsilon_{t-i}^{2}+\sum_{j=1}^{y} \delta_{j} \sigma_{t-j}^{2}
$$

where:

$\boldsymbol{N}_{\boldsymbol{t}-\boldsymbol{i}}$ is an indicator variable that represents asymmetric and leverage effects

$$
\begin{aligned}
N_{t-i} & =\left\{\begin{array}{cl}
1 & \text { if } \varepsilon_{t-1}<0 \\
0 & \text { otherwise }
\end{array}\right. \\
\ln \left(\sigma_{t}^{2}\right) & =\omega_{0}+\sum_{i=1}^{x} \propto_{i} \frac{\left|\varepsilon_{t-i}\right|+\gamma_{i} \varepsilon_{t-i}}{\sigma_{t-i}}+\sum_{j=1}^{y} \delta_{j} \ln \left(\sigma_{t-j}^{2}\right)
\end{aligned}
$$

In equation (3) $\gamma_{i}$ and $\propto_{i}$ capture the size and sign effects respectively and represent asym- $\quad 6$ metric effects. The standard GARCH can be represented by removing the leverage effect pa- $\quad 7$ rameters in either equation (3) or equation (4). The $\mathrm{ARCH}\left(\propto_{i}\right)$ and $\mathrm{GARCH}\left(\delta_{\mathrm{j}}\right)$ terms both 8 represent the persistence of the conditional variance while $\mathrm{ARCH}\left(\propto_{\boldsymbol{i}}\right)$ term represents the short 9 run effect of past innovations on the variance at time $t$. The following conditions are made for 10 the standard and GJR GARCH models to be stationary and ensure positiveness of conditional 11 variance:

$$
\begin{aligned}
\omega_{0}>0, \propto_{i} & \geq 0, \delta_{j} \geq 0 \text { and } \sum_{i=1}^{\max (x, y)}\left(\alpha_{i}+\delta_{i}+\frac{1}{2} \gamma_{i}\right) \\
& <1, \text { for } i, j
\end{aligned}
$$

In univariate models, there are cases where the persistence of the conditional variance is slightly above one (Bauwens, Hafner and Laurent 2012). Each chosen model's residuals follow 
either a Gaussian $(N)$ or Student $\mathrm{t}(t)$ distribution including their skewed counterparts, the 1 skewed normal $(s N)$ and skewed Student-t $(s t)$. The density of the residual $\left\{\varepsilon_{\mathrm{t}}=\mathrm{h}_{\mathrm{t}}^{1 / 2} \mathrm{z}_{\mathrm{t}}\right\} \quad 2$ distribution is represented collectively using Hansen (1994) skewed Student $t$ - distribution 3 where $z_{t} \sim t_{v}(v, \xi)$ as follows:

$$
f(z)=\left\{\begin{array}{l}
b c\left(1+\frac{1}{v-2}\left(\frac{b z+a}{1-\xi}\right)^{2}\right)^{-(v+1) / 2} \text { for } z<-\frac{a}{b} \\
b c\left(1+\frac{1}{v-2}\left(\frac{b z+a}{1+\xi}\right)^{2}\right)^{-(v+1) / 2} \text { for } z \geq-\frac{a}{b}
\end{array}\right.
$$

where:

$\mathrm{a}=4 \xi \mathrm{c} \frac{\mathrm{v}-2}{\mathrm{v}-1} ; \mathrm{b}^{2}=1+3 \xi^{2}-\mathrm{a}^{2}$ and $\mathrm{c}=\frac{\Gamma\left(\frac{\mathrm{v}+1}{2}\right)}{\left(\sqrt{\pi(v-2)} \Gamma\left(\frac{\mathrm{v}}{2}\right)\right)}$

In the definition of constant $c, \Gamma($.$) represents a Gamma function, 2<v<\infty$ and $-1<7$ $\xi<1$.

$$
\begin{gathered}
\mathbf{E}\left(\boldsymbol{\varepsilon}_{\mathbf{t}}\right)=\mathbf{0} \text { and } \operatorname{Cov}\left(\boldsymbol{\varepsilon}_{\mathbf{t}}\right)=\mathbf{H}_{\mathbf{t}} \\
\mathbf{H}_{\mathbf{t}}=\mathbf{D}_{\mathbf{t}} \mathbf{R}_{\mathbf{t}} \mathbf{D}_{\mathbf{t}}
\end{gathered}
$$

$\boldsymbol{D}_{\boldsymbol{t}}$ is an m by m diagonal matrix of conditional standard deviations of $\boldsymbol{\varepsilon}_{\boldsymbol{t}}$ at time $t$.

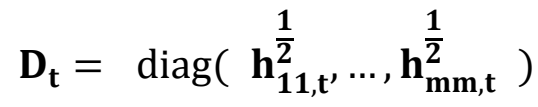

where:

- $\boldsymbol{h}_{\boldsymbol{i t}}^{\frac{1}{2}}$ above is a conditional standard deviation modelled using a univariate 14 GARCH models

- $\quad \boldsymbol{R}_{\boldsymbol{t}}$ is an $m$ by $m$ conditional symmetrical correlation (of quasi-correlations) matrix of $\varepsilon_{t}$ at time $t$ and is defined using the approach by Engle (2002)

$$
R_{t}=\operatorname{diag}\left(Q_{t}\right)^{-1 / 2} Q_{t} \operatorname{diag}\left(Q_{t}\right)^{-1 / 2}
$$




$$
Q_{t}=\left(1-\alpha_{1}-\alpha_{2}\right) \bar{R}+\alpha_{1} \bar{\varepsilon}_{t-1} \bar{\varepsilon}^{T}{ }_{t-1}+\alpha_{2} Q_{t-1}
$$

- $\boldsymbol{\alpha}_{\boldsymbol{i}}, \boldsymbol{i} \in[\mathbf{1}, \mathbf{2}]$ are non-negative scalar parameters that ensure that $\mathbf{Q}_{\mathbf{t}}$ (hence 2 $\mathbf{R}_{\mathbf{t}}$ ) remains positive definitive and for stationarity purposes have a constraint 3 that $\left(\alpha_{1}+\alpha_{2}\right)<1$

- $\overline{\boldsymbol{\varepsilon}}_{\boldsymbol{t}}$ is a vector of standardised residuals and has each element defined as follows:

$$
\text { - } \bar{\varepsilon}_{\mathrm{i}, \mathrm{t}}=\frac{\varepsilon_{\mathrm{i}, \mathrm{t}}}{\left(\mathrm{h}_{\mathrm{it}}^{1 / 2}\right)^{2}}=\frac{\varepsilon_{\mathrm{i}, \mathrm{t}}}{\sigma_{\mathrm{it}}}
$$

- $\overline{\boldsymbol{R}}$ is a symmetric matrix representing the unconditional mean of $\boldsymbol{Q}_{\boldsymbol{t}}$ and is 7 made of weighted average of the unconditional variance-covariance matrix of 8 the estimators (VCE) of the standardised residuals.

After the estimation of the varying marginal distribution families, the parameters are 10 transformed into using the probability integral transformation process to allow for their com- 11 parability. The transformed parameters are fitted in a C-MGARCH model with their joint de- 12 pendence structure estimated by a copula. A copula is a function that couples a multivariate 13 joint distribution function with its marginal distributions that are uniformly distributed (Nelsen, 14 1999). According to Sklar (1959), for an $n$-dimensional joint distribution function, 15 $\mathbf{H}=\mathbf{F}_{\mathbf{1 2 3} \ldots \mathbf{n}}$, with margins $F_{1}, F_{2}, \ldots, F_{n}$ there exists an $n$-dimensional copula $C_{\boldsymbol{S}}:{ }_{16}$ $[\mathbf{0}, \mathbf{1}]^{\mathbf{n}} \rightarrow[\mathbf{0}, \mathbf{1}]$, such that for all $\mathbf{x}_{i} \in\left(\mathbb{R}^{\mathbf{n}} \cup\{ \pm \infty\}\right)$

$$
\boldsymbol{H}\left(x_{1}, x_{2}, x_{3}, \ldots, x_{n}\right)=C_{\zeta}\left(F_{1}\left(x_{1}\right), F_{2}\left(x_{2}\right), \ldots, F_{n}\left(x_{n}\right)\right)
$$

The converse of the theorem by Sklar (1959) is that if Ç is an $n$-copula and 18 $F_{1}, F_{2}, \ldots, F_{n}$ are marginals then $\mathrm{H}$ as defined in equation (6) is a joint distribution function 19 
with marginals $F_{1}, F_{2}, \ldots, F_{n}$. If $F_{1}, F_{2}, \ldots, F_{n}$ are continuous then $C$ is unique and deter- 1 mined on $\boldsymbol{R a n}_{1} \times \boldsymbol{R a n}_{2} \quad \mathrm{x} \ldots \mathrm{x} \boldsymbol{\boldsymbol { R } a \boldsymbol { n }} F_{n}$ and each $F_{i}, i \in[1, n]$ can have unique 2 distributional attributes (Nelsen, 1999). When the assumption of continuity and differentiabil- 3 ity is considered the log-likelihood function can be defined as follows:

$$
\begin{aligned}
\log f_{12 \ldots n}\left(x_{1}, \ldots, x_{n}\right) \\
\quad=\sum_{a=1}^{n} \log \left[f_{a}\left(x_{a}\right)\right] \\
+\log \left[\zeta\left(F_{1}\left(x_{1}\right), \ldots, F_{n}\left(x_{n}\right)\right)\right]
\end{aligned}
$$

Univariate GARCH models are used in estimating the marginal loglikelihood, the ellipti- 5 cal Student $t$ copula for the copula log-likelihood function and the conditional correlation matrix parameters, $\boldsymbol{R}_{\boldsymbol{t}}$ and $\boldsymbol{\theta}=(\propto, \boldsymbol{\delta})$ for the joint likelihood. The density of the Student-t cop- $\quad 7$ ula can be expressed as follows:

$$
\begin{aligned}
& c\left(\bar{\varepsilon}_{i, t} \mid R_{i, t}, \tau\right) \\
& =\frac{\Gamma\left(\frac{\tau+k}{2}\right)\left(\Gamma\left(\frac{\tau}{2}\right)\right)^{k}\left(1+\frac{\bar{\varepsilon}_{i, t}{ }^{T} R_{i, t} \bar{\varepsilon}_{i, t}}{\tau}\right)^{-\frac{\tau+k}{2}}}{\left|R_{i, t}\right|^{\frac{1}{2}}\left(\Gamma\left(\frac{\tau+1}{2}\right)\right)^{k} \Gamma\left(\frac{\tau}{2}\right) \prod_{i=1}^{k}\left(1+\frac{\bar{\varepsilon}_{i, t}{ }^{2}}{\tau}\right)^{-\frac{\tau+1}{2}}}
\end{aligned}
$$

The loglikelihood density is separated into a copula and volatility marginals' loglikelihood as follows:

$$
\begin{aligned}
& \mathcal{L}_{i, t}\left(\theta_{i, t}, \tau\right) \text { Student } t \\
& \qquad \begin{array}{ll}
\quad & \log \frac{\Gamma\left(\frac{\tau+1}{2}\right)}{\Gamma\left(\frac{\tau}{2}\right)} \\
& -\frac{1}{2}\left(\log (\pi(\tau-2))+\log \left|D_{i, t}\right|^{2}+(\tau\right. \\
& \left.+1) \log \left(1+\frac{\varepsilon_{i, t}^{2}}{\tau-2}\right)\right)
\end{array}
\end{aligned}
$$




$$
\begin{gathered}
-\log \frac{\Gamma\left(\frac{\tau+k}{2}\right)}{\Gamma\left(\frac{\tau}{2}\right)}-k \log \frac{\Gamma\left(\frac{\tau+1}{2}\right)}{\Gamma\left(\frac{\tau}{2}\right)}-\frac{\tau+k}{2} \log \left(1+\frac{\bar{\varepsilon}_{i, t}{ }^{T} R_{i, t} \bar{\varepsilon}_{i, t}}{\tau}\right) \\
-\log \left|R_{i, t}\right|-\frac{\tau+1}{2} \sum_{i=1}^{k}\left(1+\frac{\bar{\varepsilon}_{i, t}{ }^{2}}{\tau}\right)
\end{gathered}
$$

$\boldsymbol{\Gamma}($.$) and \boldsymbol{\tau}$ represent a Gamma distribution function and degrees of freedom, respectively and 2 $\bar{\varepsilon}_{\mathrm{i}, \mathrm{t}}$ represents standardized residuals. The estimation process uses R's rugarch and rmgarch 3 packages of Ghalanos (2013).

\section{Data Analysis, Results and Discussion}

The estimation process uses R's rugarch and rmgarch packages of Ghalanos (2013). The models used for the marginal distributions and their estimations are shown in Table 2 and Table 3 (a and b), respectively. The exponential and GJR GARCH better model 59\% of the sampled univariates relative to the standard GARCH. The prevalence use of asymmetric volatility models is an indicator of leverage effect in the univariates. The varying volatility impact from previous shocks exists for crude oil and gold; both stock and currency markets of Algeria, Ghana, 11 Nigeria and Zambia; stock markets of South Africa, Tunisia, Uganda and Morocco; and cur- 12 rencies of Angola, DRC, Ethiopia, Egypt, Côte d'Ivoire, Tanzania. Non-normality and lepto- 13 kurtosis of the residuals can be deduced from the significance of the skewness and shape pa- 14 rameters in the residual distribution.

In Tables 3 (a) and 3 (b), the following applies: $* * * \Rightarrow$ Statistical significance at $10 \%$; ** $\Rightarrow>17$ statistical significance at $5 \%$ and $^{*}=>$ statistical significance at $1 \%$. 
Table 4 shows an initial estimation of the copula which is a dependence structure of the 1 marginals per economy; results of the nonconsistency test suggested by Bücher et al.(2014), 2 amongst others, to confirm whether a dynamic or static dependence measure would be appro- 3 priate and a goodness of fit test for the Student- $t$ copula. The results in Table 4 show that, at a 4 $5 \%$ level of significance, Kenya variables' dependence structure requires a time varying copula 5 while that of Ethiopia, Libya, Nigeria, Sudan, Tanzania and Tunisia would require a different 6 copula other than the Student $t$ copula. We fit a dynamic dependence structure using a Student $\quad 7$ $t$ copula DCC-GARCH and report in Table 5 the estimates of the joint scalar parameters which 8 are useful in determining the dynamic dependence pattern. At a 5\% level of significance the 9 results of Table 5 show that not all the scalar parameters are significant, and that the constant 10 correlation assumption would fit the dynamic dependence process of economies of: Angola, 11 Ethiopia, Kenya, Libya, Morocco, Sudan and Tunisia. Table 5 also shows cases where at least 12 one of the scalar joint parameters is significant at $5 \%$ for economies of Algeria, Botswana, 13 Ivory Coast, Egypt, Ghana, Nigeria, Uganda, South Africa, Tanzania and Zambia. The models 14 fitted for all economies except Egypt, South Africa, Sudan, Tanzania, Libya and Zambia show 15 the dynamic dependence oscillating around the period average dependence measured and re- 16 quire a scaling factor approach to visualise.

The scaling is done only for visualising the movement of the dependence measure and is applied for each estimated DCC-GARCH element at time $i$ for a vector of length $T, \widetilde{\mathbf{D}}_{\mathbf{i}}=\quad 19$

$$
\operatorname{DCC}_{\mathrm{i}} 10^{10}-10^{3}\left(\sum_{\mathrm{i}=1}^{\mathrm{T}} \mathrm{DCC}_{\mathrm{i}} / \mathrm{T}\right) 10^{7}
$$

We report on the period average for the all economies in Table 6 and present a visualisa- $\quad 21$ tion of the dynamic dependence from Figure A1 to Figure A15. (Figures A4 to A15 are in- 22 cluded as supplementary material). In each visualisation, notable global events have been em- 23 bedded to show changes in the bivariate association surrounding each event. The embedded 24 
events include; the technology stocks bubble that took place in March 2000; terror related in- 1 cident that took place in the USA during September 2001; 2008 global financial crisis; Euro- 2 zone bond crisis from December 2009 and oil price plunge of July 2014.

In the fitted models there is a positive dependence between oil and gold that has down- 4 ward trend post the 2014 oil crisis. Tanzania (with main export goods, gold and tobacco) and 5 Ethiopia (gold and coffee) are the only economies that on average have a positive relationship 6 amongst the sampled variables. For Ethiopia, dependence has an incremental change between $\quad 7$ the currency and commodities relation during the 2008 crisis, but has a varying reaction post 8 the 2014 oil crisis, where oil and ETB association increased while that of the ETB and gold 9 decreased. For Tanzania, dependence amongst variables start at low or negative values and 10 grows around 2009 for TZS, oil and gold bivariate relationships but around 2014 for the 11 DSEAI, oil and gold relationships. The relationship between the TZS and DSEAI also peaks 12 during of the 2014 oil price plunge and during this period there is a trend increase in the TZS, 13 DSEAI and oil bivariate relationships. Egypt (oil), Tunisia (cotton and olive oil) and Uganda 14 (gold and cocoa) are economies that each have on average a positive relationship between their 15 stock market and all other variables and a negative dependence relationship between their cur- $\quad 16$ rencies and sampled commodities. For Egypt, the dependence between the EGP and EGX30 17 falls during the 2004 and 2005 period and this occurrence can be a reaction to the currency 18 devaluing decision of 2003 by the domestic central bank. The EGP and EGX30 association 19 start increasing post the 2008 market crisis. During the 2008 financial crisis there is also a 20 notable stepwise change in the gold, oil and EGX30 bivariate relationships that is a sign of a 21 market reaction as the relationship amongst the variables reaches their peak dependence and 22 sharply decreases after each highlighted oil market crash and this occurs during a period when 23 the EGP is again allowed by the central bank to float from a pegging structure. Uganda's fitted 24 
model shows an abrupt change that occurs during 2008 financial crisis, the change is amongst 1 all the variables and gets sustained post the crisis period. 2

Crude oil has special cases such as those mentioned for Tanzania and Ethiopia and for 3 economies of Sudan (oil and gold) and Ghana (gold, cocoa and oil), where oil is positively 4 associated with currency. The model for Sudan shows association measures per variable around 5 the average and experienced a shift during the 2008 crisis. Nigeria (oil) and DRC (copper) are 6 economies indicating a positive association between their currencies and gold. For Nigeria, 7 both the 2008 and 2014 oil price plunge show a market reaction that also shows gold as a 8 currency haven for the economy's export market and this is due to the observed positive in- 9 crease in the NGN and gold association that occurs during and post the oil price plunges. The 10 relationship between NGN and gold shows a stable association measure that has a step change 11 during the 2008 and 2014 oil crises. The step change is also observable in the association 12 amongst other variables in the model for the Nigerian economy. CDF has associations amongst $\quad 13$ oil and gold that are relatively stable but show a step change during the 2008 and 2014 oil 14 crises for both commodities. These changes, as DRC is a copper exporter, could be signals of 15 changes in production additives price and a co-movement in the commodity markets in general. 16 The currencies of Libya (oil and diamonds) and Angola (oil and gas) have a negative co-move- $\quad 17$ ment relationship with the sampled commodities. For Libya there is an increase in the negative 18 association that changes direction after 2009, but both the 2008 and 2014 oil price plunge had 19 a visible impact in the LYD. For Angola, there is a downward trend that is sustained by the 20 AOA and gold relationship pre-2009 that changes direction after 2009 while that of AOA and 21 oil has an upward trend until the beginning of the 2014 oil price plunge.

There is a negative association between equity and currency markets for Kenya (oil, tea 23 and flowers), Morocco (vehicles, chemical acids and electrical equipment) and South Africa 24 (gold and platinum). The model fitted for Morocco shows changes in trend that occur around 25 
2004 and 2011 for the MASI, gold and oil relationship; mid 2009 for the MAD, oil and gold relationship; and a downward trend in the MAD and MASI association that starts during the 2 2014 oil price plunge. South Africa's fitted variables show significant changes in their levels 3 of association during the sampled period, where the included financial crises only show an 4 impact in the ZAR and gold association during the 2008 crisis. There is an abrupt downward 5 trend of association that occurs around the 2014 oil price plunge for all variables. The stock 6 markets of Algeria (oil and gas) and Botswana (diamonds) have low negative average depend- $\quad 7$ ence measure between them, crude oil and gold that are below 5\%. The model fitted for Zambia 8 (copper) shows that the rebasing of the currency had an impact that affected all markets around 9 2011 while the 2014 oil price plunge affected the association amongst equity, currency, and 10 gold markets, though this is not fully visible in the currency and gold markets. Côte d'Ivoire' 11 XOF is negatively dependent to both oil and gold. The negative relationship can be attributed 12 to having a mixture of exported commodities by the regional constituents. For instance, within 13 the region there are economies; Benin (gold), Burkina Faso (gold), Guinea-Bissau (cashew 14 nuts), Mali (gold), Niger (gold), Senegal (gold and oil), Togo (gold and oil) and Côte d'Ivoire 15 (cocoa). The BRVMCI has relatively low dependence to both oil and gold.

The results presented on the relationship amongst the variables are conditional on the 17 economy as they are not consistent. In general, the findings around gold and oil association 18 with currencies agree with those of Yang et al. (2018) who find the negative effect of oil on 19 currency; those of Bedoui et al. (2018) who find that there is a positive influential relationship 20 between oil and gold. The finding of stock market being influenced by commodities agree in 21 general with those of $\mathrm{Xu}$ et al. (2019) who find the asymmetric relationship between oil and 22 stock markets and those of Nguyen et al. ( 2016) who find the influence of stock markets from 23 gold. The findings by Jain and Biswal (2016) are also in agreement as they also find a positive 24 association between oil, gold and the Indian stock market and currency. Limited by approach 25 
our results are not in disagreement with those of Fowowe (2015) and of Ahmed ( 2014) who 1

both find a unidirectional influence between stock markets and currencies of Nigeria, South 2

Africa and Egypt.

\section{Conclusions}

Most economies in the African continent have a high proportion of total exports compris- 5 ing of a single or few commodities. Gold and crude oil are amongst the most commonly ex- 6 ported commodities and are used as proxy to the commodities market in this paper. This paper $\quad 7$ presents a study on the dynamic dependence amongst commodities, exchange rates and stock 8 markets using a Student $t$ copula DCC-GARCH framework and economies that were large in 9 the African continent during the sampled period of January 2000 - December 2019. The study 10 includes economies of Algeria, Angola, Botswana, DRC, Côte d'Ivoire, Egypt, Ethiopia, 11 Ghana, Kenya, Libya, Morocco, Nigeria, South Africa, Sudan, Tanzania, Tunisia, Uganda and 12 Zambia.

The results initially show asymmetric impact from positive and negative past shocks of $\quad 14$ an asset to both their future counterparts and volatility; however, this impact is also found to 15 be associated with and dependent on behaviour in other markets. Dependence from price fluc- 16 tuations amongst the sampled markets is time varying and evolves at a scale around the average $\quad 17$ dependence measure for most economies but has relatively larger shifts for the economies of 18 Egypt, South Africa, Sudan, Tanzania, Libya and Zambia. In all the fitted models there is a 19 positive association between oil and gold. Most currencies on average have a negative associ- $\quad 20$ ation with sampled commodities except for Tanzania and Ethiopia. Even though a high share 21 of crude oil makes up total exports of Angola, Algeria, Egypt, Ghana Nigeria, Sudan and Libya 22 but there is not enough evidence to argue that there is high association of their local currency 23 with the movements of crude oil prices such that the level of dependence in some instances is 24 quantitatively greater for gold than oil. Gold and oil also have a positive association with stock 25 
markets except for economies of Algeria, Botswana, Côte d'Ivoire, Kenya, Morocco and Su- 1 dan. Stock markets and exchange rates have a varying low dependence relationship per econ- 2 omy that is above $10 \%$ for Botswana, Côte d'Ivoire and South Africa.

Carbon emissions are capturing global attention and could imply a change in global en- 4 ergy consumption that shifts away from fossil generated and towards renewable and cleaner 5 energy sources. This could mean a change in current demand of exported commodities that is 6 likely to influence financial variables such as stock markets and currencies of African econo- $\quad 7$ mies. The results of this study can be used by policymakers in understanding how dependencies 8 influence current and ongoing risks and benefits in areas such as trading, production, supply 9 chain and investment. Further studies in the area of dependence can improve inferences by 10 studying dependence at varying regimes, higher frequency and dynamic tail behaviour captur- $\quad 11$ ing models.

\section{Declarations}

Ethics approval and consent to participate:

Ethics approval was granted for this research by the University of South Africa. (ERC Reference \#: 2020/CSET/SOS/017 (Dated 04 June, 2020)

Consent for publication: Both authors have read and agreed to the published version of 18 the manuscript in JECS.

Data Availability Statement: The data used in this research is available from the Authors by request. 
Author Contributions: Conceptualization, J.O.O. and T.H.M.; methodology, J.O.O. and

T.H.M.; validation, J.O.O; data curation, T.H.M; formal analysis, T.H.M; writing—original 2 draft preparation, T.H.M; and writing — review and editing, J.O.O; supervision, J.O.O.

\section{Acknowledgements}

We would like to appreciate the teams from Botswana Stock Exchange, Egypt Stock Exchange, $\quad 5$ and Johannesburg Stock Exchange for the data they entrusted with us to use as part of the 6 analysis for this paper.

Authors' information (optional): $\quad$ Not Applicable $\quad 8$

References

Adams Z, Füss R. Kaiser D. G (2011) Macroeconomic Determinants of Commodity Futures 12 Returns. The Handbook of Commodity Investing. (Wiley Online Books), 87-112. doi: 13 https://doi.org/10.1002/9781118267004.ch4.

Adewuyi Adeolu O, Olabanji B Awodumi, Temitope T Abodunde (2019) Analysing the Gold- 15

Stock Nexus Using VARMA-BEKK-AGARCH and Quantile Regression Models: New 16 Evidence from South Africa and Nigeria. Resources Policy 61 (February): 348-62. 17 https://doi.org/10.1016/j.resourpol.2019.02.015.

African Economic Outlook (2017) African Economic Outlook. OECD. 19 https://doi.org/10.1787/aeo-2017-en. 
Stock Markets: Evidence from Emerging African Economies. Applied Economics 52 (18): 1 1921-35. https://doi.org/10.1080/00036846.2020.1726861.

Ahmed Walid M.A (2014) Dynamic Interactions between Egyptian Equity and 3 CurrencyMarkets Prior to and during Political Unrest. Applied Financial Economics 24 (20): 4 1347-59. https://doi.org/10.1080/09603107.2014.925061.

Arouri Mohamed El Hedi, Jamel Jouini, Duc Khuong Nguyen (2012). On the Impacts of Oil 6 Price Fluctuations on European Equity Markets: Volatility Spillover and Hedging 7 Effectiveness. Energy Economics 34 (2): 611-17. https://doi.org/10.1016/j.eneco.2011.08.009. 8 Bank World (2018) Global Economic Prospects, January 2018: Broad-Based Upturn, but for 9 How Long? Global Economic Prospects. The World Bank. https://doi.org/10.1596/978-1- 10 4648-1163-0.

Basher Syed Abul, Alfred A. Haug, Perry Sadorsky (2016) The Impact of Oil Shocks on 12 Exchange Rates: A Markov-Switching Approach. Energy Economics 54: 11-23. 13 https://doi.org/10.1016/j.eneco.2015.12.004.

Baur Dirk G, Thomas K. McDermott (2010) Is Gold a Safe Haven? International Evidence. 15 Journal of Banking and Finance $34 \quad$ (8): $1886-98 . \quad 16$ https://doi.org/10.1016/j.jbankfin.2009.12.008.

Baur Dirk G, Thomas K.J. McDermott (2016) Why Is Gold a Safe Haven? Journal of 18 Behavioral and Experimental Finance 10: 63-71. https://doi.org/10.1016/j.jbef.2016.03.002. 19 Bauwens Luc, Christian Hafner, Sebastien Laurent. (2012) Handbook of Volatility Models and 20 Their Applications. Vol. 91. https://doi.org/10.1017/CBO9781107415324.004. 
Bedoui Rihab, Sana Braeik, Stéphane Goutte, Khaled Guesmi (2018) On the Study of 1 Conditional Dependence Structure between Oil, Gold and USD Exchange Rates. International 2 Review of Financial Analysis 59: 134-46. https://doi.org/10.1016/j.irfa.2018.07.001.

Behmiri Niaz Bashiri, Matteo Manera (2015) The Role of Outliers and Oil Price Shocks on 4 Volatility of Metal Prices. Resources Policy 46: 139-50. 5 https://doi.org/10.1016/j.resourpol.2015.09.004.

Bera Anil K, Carlos M Jarque (1981) Efficient Tests for Normality, Homoscedasticity and 7 Serial Independence of Regression Residuals. Journal of the American Statistical Association 8 7: $313-18$.

Blau Benjamin M. (2018) Exchange Rate Volatility and the Stability of Stock Prices. 10 International Review of Economics and Finance 58 (October 2015): 299-311. 11 https://doi.org/10.1016/j.iref.2018.04.002.

Branson William (1981) Macroeconomic Determinants of Real Exchange Rates. Cambridge, 13 MA. https://doi.org/10.3386/w0801.

Bücher Axel, Ivan Kojadinovic, Tom Rohmer, Johan Segers (2014) Detecting Changes in 15 Cross-Sectional Dependence in Multivariate Time Series. Journal of Multivariate Analysis 132: 16 111-28. https://doi.org/10.1016/j.jmva.2014.07.012.

Chkili Walid (2016) Dynamic Correlations and Hedging Effectiveness between Gold and 18 Stock Markets: Evidence for BRICS Countries. Research in International Business and 19 Finance 38 (1): 22-34. https://doi.org/10.1016/j.ribaf.2016.03.005. 
a Regime-Switching Environment: Evidence for BRICS Countries. Research in International 1

Business and Finance 31: 46-56. https://doi.org/10.1016/j.ribaf.2013.11.007.

Choudhry Taufiq, Syed S. Hassan, Sarosh Shabi (2015) Relationship between Gold and Stock 3

Markets during the Global Financial Crisis: Evidence from Nonlinear Causality Tests. 4 International Review of Financial Analysis $41: \quad 247-56 . \quad 5$ https://doi.org/10.1016/j.irfa.2015.03.011. 6

Ciner Cetin, Constantin Gurdgiev, Brian M. Lucey (2013) Hedges and Safe Havens : An 7 Examination of Stocks, Bonds, Gold, Oil and Exchange Rates. International Review of 8 Financial Analysis 29: 202-11. https://doi.org/10.1016/j.irfa.2012.12.001. 9

Couharde Cécile, Audrey Sallenave (2013) How Do Currency Misalignments' Threshold 10 Affect Economic Growth? Journal of Macroeconomics 36: 106-20. 11 https://doi.org/10.1016/j.jmacro.2012.11.002.

Deaton Angus (1999) Prices and Growth in Africa Conmmodity. Journal of Economic 13 Perspectives 13 (3): 23-40.

Degiannakis Stavros, Filis George, Arora Vipin (2018) Oil Prices and Stock Markets: A 15 Review of the Theory and Empirical Evidence. Energy Journal, Vol. 5, No. 39: 85-130.

Degiannakis Stavros, George Filis, Christos Floro (2013) Oil and Stock Returns: Evidence 17 from European Industrial Sector Indices in a Time-Varying Environment. Journal of 18 International Financial Markets, Institutions and Money 26: 175-91. 19 https://doi.org/10.1016/j.intfin.2013.05.007. 
Elbadawi Ibrahim A, Linda Kaltani, Raimundo Soto (2012) Aid, Real Exchange Rate 2 Misalignment, and Economic Growth in Sub-Saharan Africa. World Development 40 (4): 681- 3 700. https://doi.org/10.1016/j.worlddev.2011.09.012.

Engle Robert (2002) Dynamic Conditional Correlation. Journal of Business \& Economic 5 Statistics 20 (3): 339-50. https://doi.org/10.1198/073500102288618487.

Filis George, Stavros Degiannakis, Christos Floros. (2011) Dynamic Correlation between 7 Stock Market and Oil Prices: The Case of Oil-Importing and Oil-Exporting Countries. 8 International Review of Financial Analysis $\quad 20: \quad 152-64.9$ https://doi.org/10.1016/j.irfa.2011.02.014. 10 Fowowe Babajide (2015) The Relationship between Stock Prices and Exchange Rates in South 11 Africa and Nigeria: Structural Breaks Analysis. International Review of Applied Economics 12 29 (1): 1-14. https://doi.org/10.1080/02692171.2014.933786.

Frankel Jeffrey (1983) Monetary and Portfolio Balance Models of Exchange Rate 14 Determination. In Economic Interdependence and Flexible Exchange Rates, 84-115.

Ghalanos Alexios (2013) The Rmgarch Models : Background and Properties. Version 1.2-6. 16 https://www.semanticscholar.org/paper/The-rmgarch-models\%3A-Background-andproperties.-Ghalanos/4b63df469d5b1e4ce5cd84e92727c200510f8d07

Glosten Lawrence R, Ravi Jagannathan, David E Runkle (1993) On the Relation between the 19 Expected Value and the Volatility of the Nominal Excess Return on Stocks. Journal of Finance, $\quad 20$ XLVIII (5): 1779-1801. 
Hansen Bruce E (1994) Autoregressive Conditional Density Estimation. International 1 Economic Review 35 (3): 705-30.

Jain Anshul, P. C. Biswal (2016) Dynamic Linkages among Oil Price, Gold Price, Exchange 3 Rate, and Stock Market in India. Resources Policy 49: 179-85. 4 https://doi.org/10.1016/j.resourpol.2016.06.001.

Joy Mark (2011) Gold and the US Dollar: Hedge or Haven? Finance Research Letters 8 (3): 6 120-31. https://doi.org/10.1016/j.frl.2011.01.001.

Junttila Juha, Juho Pesonen, Juhani Raatikainen (2018) Commodity Market Based Hedging 8 against Stock Market Risk in Times of Financial Crisis: The Case of Crude Oil and Gold. 9 Journal of International Financial Markets, Institutions and Money 56: 255-80. 10 https://doi.org/10.1016/j.intfin.2018.01.002.

Lee T. H, Long, X (2009) Copula-based multivariate GARCH model with uncorrelated 12 dependent errors. Journal of Econometrics, 150(2), 207-218. doi: 13 10.1016/j.jeconom.2008.12.008.

Malandala K, Olaomi J.O (2021) Analysis of the dependence structure between minerals prices 15 and the Rand/USD exchange rate using copulas. Studies in Economics and Econometrics, 44(3), 16 pp. 73-107. https://www.tandfonline.com/doi/full/10.1080/03796205.2020.1919425

Milani Fabio (2011) The Impact of Foreign Stock Markets on Macroeconomic Dynamics in 18 Open Economies: A Structural Estimation. Journal of International Money and Finance 30 (1): 19 111-29. https://doi.org/10.1016/j.jimonfin.2010.07.005. 
Prices: Evidence from Developed and Emerging Asian Markets. International Review of 1 Economics and Finance 29: 1-11. https://doi.org/10.1016/j.iref.2013.02.004.

Ncube Mthuli, Dawit B Tessema, Daniel Zerfu Gurara (2014) Volatility and Co-Movement in 3

Commodity Prices: New Evidence 205. African Development Bank,Tunis, Tunisia.

Nelsen Roger B (1999) Introduction to Copulas. https://doi.org/10.1007/978-1-4757-3076-0. 5

Nelson Daniel (1991) Conditional Heteroskedasticity in Asset Returns: A New Approach. 6

Econometrica 59 (2): 347-70. https://doi.org/10.2307/2938260.

Nguyen Cuong, M. Ishaq Bhatti, Magda Komorníková, Jozef Komorník (2016) Gold Price and 8 Stock Markets Nexus under Mixed-Copulas. Economic Modelling. 9 https://doi.org/10.1016/j.econmod.2016.05.024.

O’Connor F, Lucey B, Batten J, Baur D (2015) The Financial Economics of Gold - A Survey. 11 International Review of Financial Analysis, 41, 186-205).

Partha Deb, Pravin K Trivedi, Panayotis Varangis (1996) The Excess Co-Movement of 13 Commodity Prices Reconsidered 11 (3): 275-91.

Phillips Peter C.B, Pierre Perron (1988) Testing for a Unit Root in Time Series Regression. 15 Biometrika 75 (2): 335-46. https://doi.org/10.1093/biomet/75.2.335.

Pindyck Robert S, Julio J. Rotemberg. (1990) The Excess Co-Movement of Commodity Prices. 17 The Economic Journal 100 (403): 1173-89.

Raza Naveed, Syed Jawad Hussain Shahzad, Aviral Kumar Tiwari, Muhammad Shahbaz (2016) 19 Asymmetric Impact of Gold, Oil Prices and Their Volatilities on Stock Prices of Emerging 20 Markets. Resources Policy. https://doi.org/10.1016/j.resourpol.2016.06.011. 
Reboredo J. C (2013) Is gold a safe haven or a hedge for the US dollar? Implications for risk 1 management. Journal of Banking and Finance, 37(8), 2665-2676. doi: 2 10.1016/j.jbankfin.2013.03.020.

Reboredo J. C, Ugolini A (2016) Quantile dependence of oil price movements and stock returns. 4 Energy Economics, 54, 33-49. doi: 10.1016/j.eneco.2015.11.015.

Shapiro A. S. S, Wilk M. B (1965) An Analysis of Variance Test for Normality (Complete 6 Samples). Biometrika Trust, 52(3/4), 591-611.

Sklar A (1959) Fonctions de repartition a n dimensions et leurs marges. Publ. Inst. Statist. Univ. 8 Paris, 8, 229-231. Available at: http://ci.nii.ac.jp/naid/10011938360/en/ (Accessed: 7 March 9 2021).

Tang B (2015) Real exchange rate and economic growth in China: A cointegrated VAR 11 approach. China Economic Review. Elsevier Inc., 34, 293-310. doi: 12 10.1016/j.chieco.2014.12.002.

Tsay R (2010) Analysis of Financial Time Series. 3rd edn. Chicago.

United Nations Conference on Trade and Development (2019) Commodity Dependence : A 15 Twenty-Year Perspective.

Wang Y, Wu C, Yang, L (2013) Oil price shocks and stock market activities : Evidence from 17 oil-importing and oil-exporting countries. Journal of Comparative Economics. Association for 18 Comparative Economic Studies, 41(4), 1220-1239. doi: 10.1016/j.jce.2012.12.004. 
Yan H.D, Yang C. L (2012) Does an Undervalued Currency Merit Economic Growth? - 2 Evidence from Taiwan. Panoeconomicus, 59(1), 37-57. doi: 10.2298/PAN1201037Y.

Yang L, Yang Lu, Cai X. J, Hamori S (2018). What determines the long-term correlation 4 between oil prices and exchange rates?. The North American Journal of Economics and Finance, 44, 140-152. doi: https://doi.org/10.1016/j.najef.2017.12.003.

Zankawah M. M, Stewart, C (2019) Measuring the volatility spill-over effects of crude oil prices on the exchange rate and stock market in Ghana. The Journal of International Trade \& Economic Development. 29(4), 420-439. doi: 10.1080/09638199.2019.1692895. 
Figures
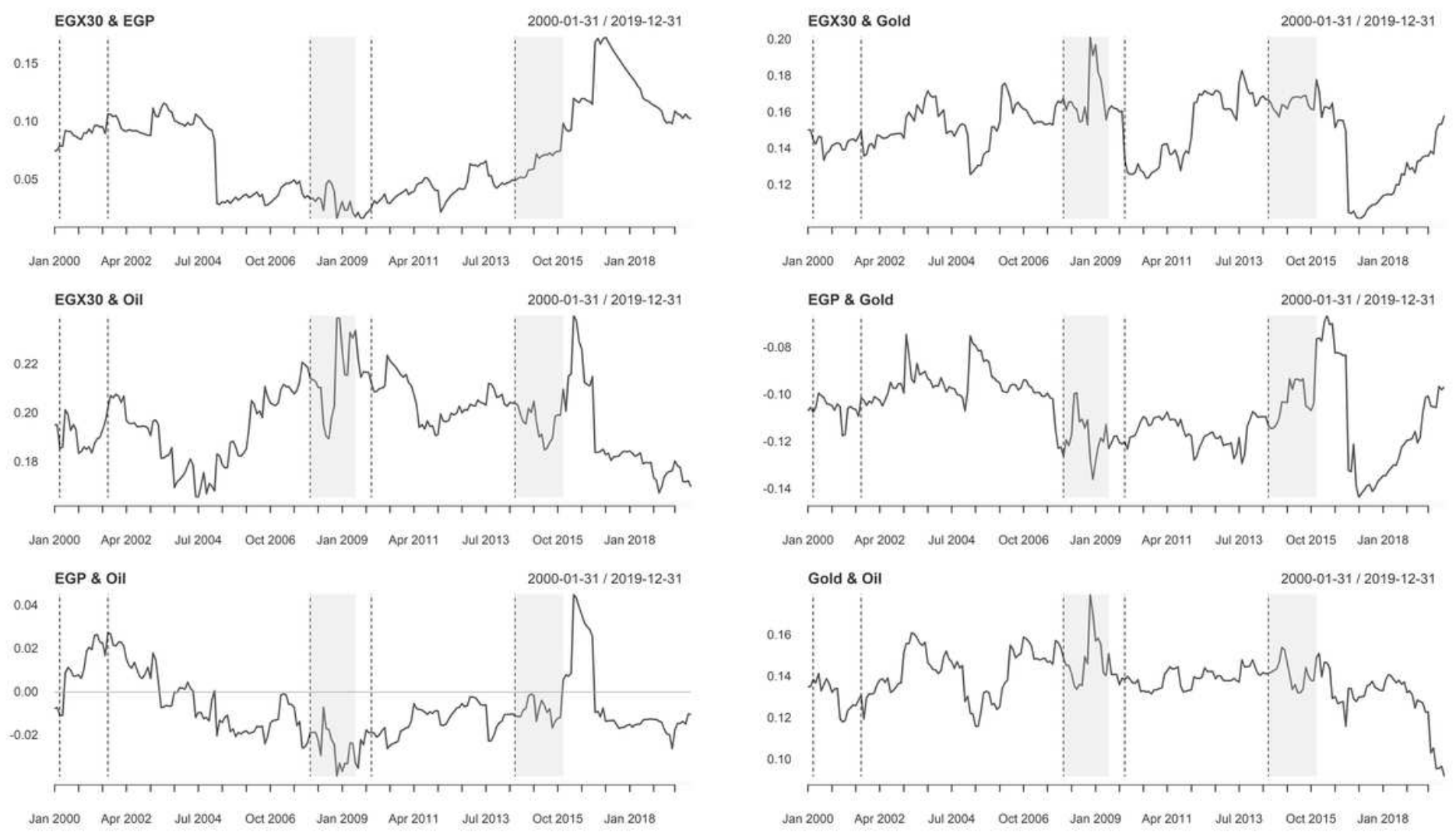

Figure 1

Please see the Manuscript PDF file for the complete figure caption 

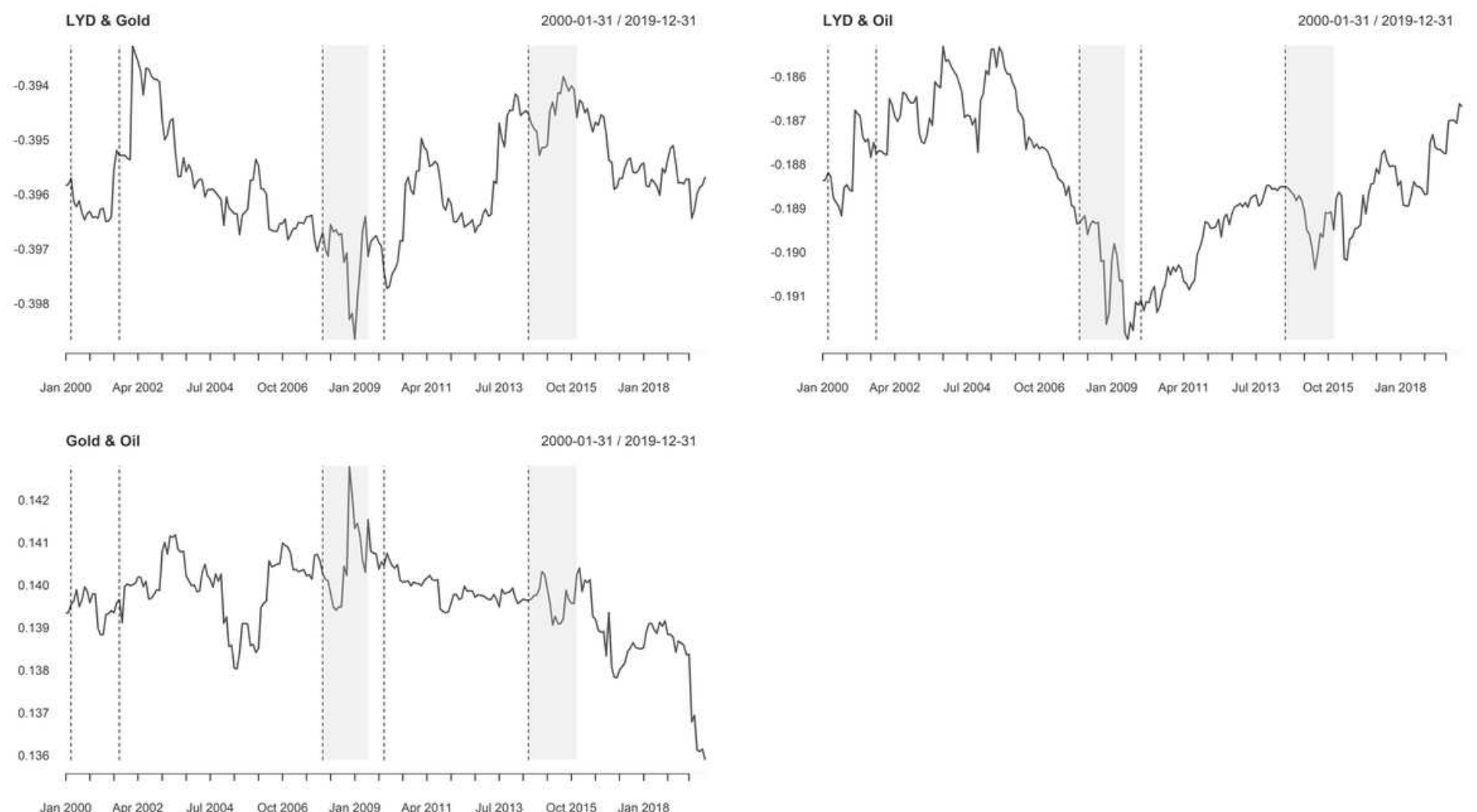

Figure 2

Please see the Manuscript PDF file for the complete figure caption

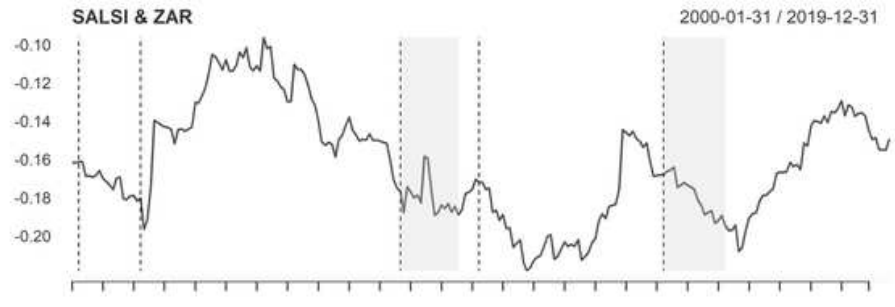

$\begin{array}{llllllll}\text { Jan } 2000 \text { Apr } 2002 & \text { Jul } 2004 & \text { Oct } 2006 & \text { Jan } 2009 & \text { Apr } 2011 & \text { Jul } 2013 & \text { Oct } 2015 & \text { Jan } 2018\end{array}$

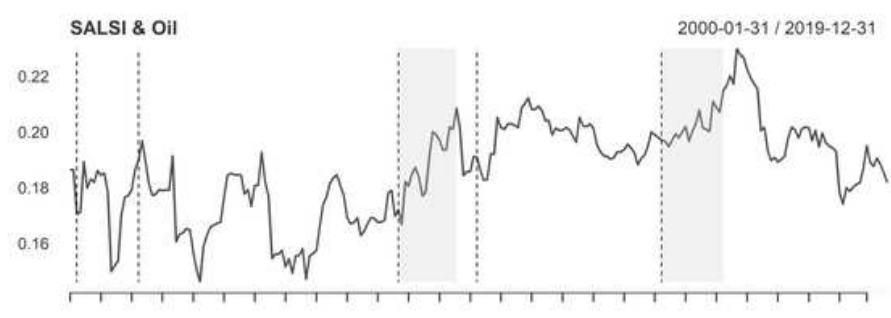

Jan 2000 Apr 2002 Jul 2004 Oct 2006 Jan 2009 Apr 2011 Jul 2013 Oct 2015 Jan 2018

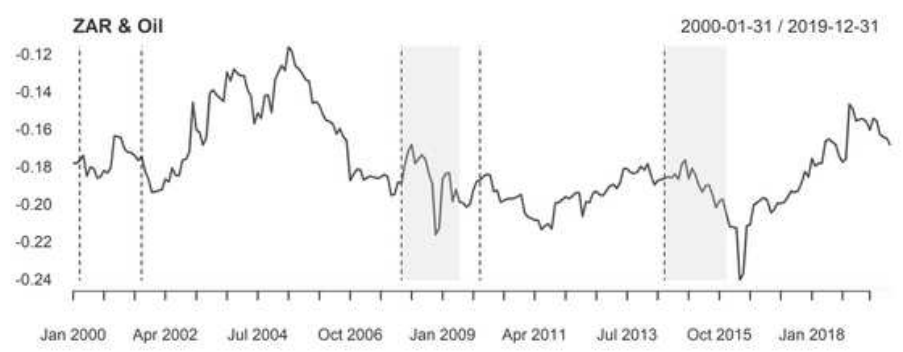

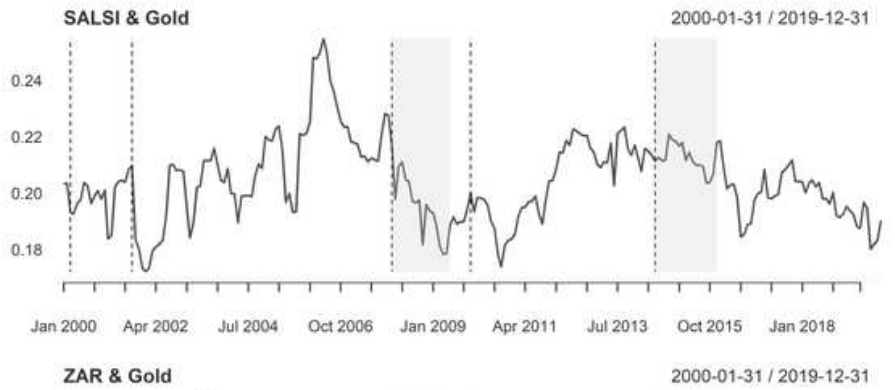

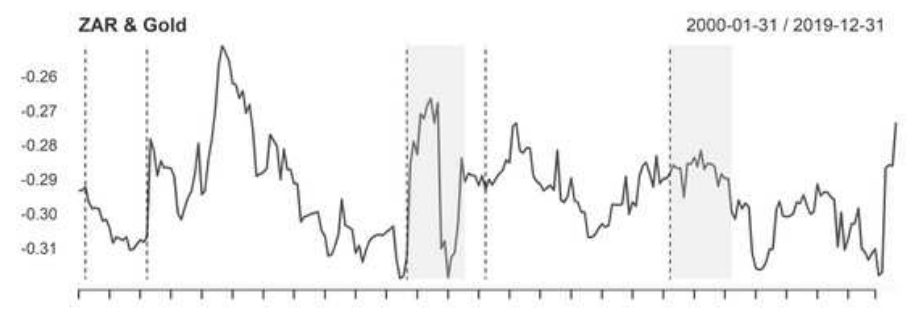

Jan 2000 Apr 2002 Jul 2004 Oct 2006 Jan 2009 Apr 2011 Jul 2013 OCt 2015 Jan 2018

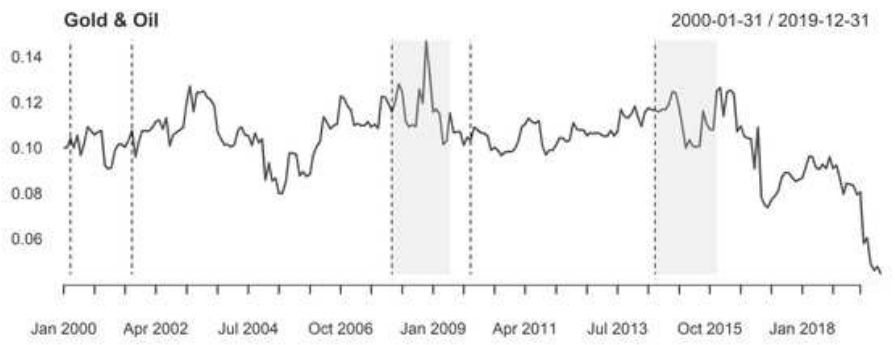

Figure 3 
Please see the Manuscript PDF file for the complete figure caption

\section{Supplementary Files}

This is a list of supplementary files associated with this preprint. Click to download.

- OnlineFigureA1DCCAlgeria.png

- OnlineFigureA2DCCAngola.png

- OnlineFigureA3DCCBotswana.png

- OnlineFigureA4DCCCotedlvoire.png

- OnlineFigureA5DCCDRC.png

- OnlineFigureA6DCCEthiopia.png

- OnlineFigureA7DCCGhana.png

- OnlineFigureA8DCCKenya.png

- OnlineFigureA9DCCMorocco.png

- OnlineFigureA10DCCNigeria.png

- OnlineFigureA11DCCSudan.png

- OnlineFigureA12DCCTanzania.png

- OnlineFigureA13DCCTunisia.png

- OnlineFigureA14DCCUganda.png

- OnlineFigureA15DCCZambia.png 